\title{
Wide-range tunable subwavelength band-stop filter for the far- infrared wavelengths based on single-layer graphene sheet
}

\author{
Mohammed Nadhim Abbas and Farooq Abdulghafoor Khaleel \\ Department of Electrical Engineering, College of Engineering, University of \\ Baghdad, Al-Jadriya, Iraq, mohammed.nadhim@uob.edu.iq
}

Received: 16.01 .2019

\begin{abstract}
A subwavelength metamaterial consisting of array of aluminium conductors is proposed and numerically analyzed using a finite-element method. This material is suggested for a tunable active band-stop filter working in the farinfrared region. A cell of our metamaterial-based structure is composed of a rhombic-shaped aluminium conductor, a rubidium-bromide dielectric, and a graphene sheet deposited on the dielectric in order to achieve tunability. A strong confinement of electromagnetic energy absorbed in the dielectric results in a highly efficient absorption. The suggested structure with the graphene sheet exposed to air can act as a highly sensitive refractive-index sensor (the sensitivity $6.8 \mu \mathrm{m} / \mathrm{RIU}$ ). Due to a small size of our structure, it reveals perfect absorption at the far-infrared wavelengths and wide-range absorption tuning (from 23.6 to $38.1 \mu \mathrm{m}$ ). The metamaterials with the above structure can result in perfect absorbers for biomedical sensing.
\end{abstract}

Keywords: subwavelength structures, plasmonic devices, far-infrared absorbers, graphene, band-stop filters, finite-element method

PACS: 42.79.Ci, 78.30.-j

UDC: $535-15,535.345 .6$

\section{Introduction}

Recently a far-infrared wavelength region (3-100 $\mu \mathrm{m}$, according to classification of the International Commission on Illumination) has been extensively studied. Appropriate devices can be applied in such fields as biomedical and chemical sensing, photo-thermal transformations, photodetection, optical modulation and switching, multispectral imaging and colour printing $[1,2]$. Plasmonic effects play a major role in high-speed data transmission and nanoelectronic technologies aimed at confining, storing, guiding and enhancing locally electromagnetic waves in the far-infrared region [3].

Optical near fields in subwavelength structures are excited due to links between conduction electrons and electromagnetic waves in small metallic nanostructures. A metamaterial structure is a periodic device with a certain engineered shape and subwavelength geometry that controls propagation of electromagnetic waves. A rapid growth of both metamaterial and plasmonic technologies has encouraged researchers to investigate various plasmonic metamaterial structures [4]. Such two-dimensional (2D) materials as, e.g., hexagonal boron nitride, transition metal dichalcogenides and graphene have become a hot topic in many earlier researches because of their promising optical and electrical characteristics [5].

Graphene represents one of the most interesting 2D materials with a single-atomic thickness. The majority of its electrons can conduct because of massive intraband transitions in the farinfrared wavelength region [6,7]. Plasmons in graphene confine the fields to extreme extent. They reveal very low damping losses, in addition to the most significant feature, tuning of conductivity 
via a voltage bias [8]. Interesting optical and electrical properties of graphene have led to development of a new generation of optical and electrical nanodevices. These are polarizers [9], filters [10], perfect absorbers [11, 12], refractive-index sensors [13, 14], modulators [15], photonic crystals [16], transforming optical devices [17], etc.

Many recent studies have demonstrated great resources of graphene in tuned absorption of electromagnetic waves, which is achieved via tuning of graphene's chemical potential. For example, the active band-stop filter presented in Ref. [2] can achieve a tuned dual-band filtering response from 11.8 to $13.4 \mu \mathrm{m}$ or from 16.6 to $18.5 \mu \mathrm{m}$. Nonetheless, the tuning range mentioned above is still too narrow and does not cover a desirable wide range of far-infrared frequencies. In the other study [10] that presents a multi-layer graphene-based tunable band-pass filter, a graphene waveguide composed of six single-layer graphene sheets shows dual-band filtering for 1.508 and $1.545 \mu \mathrm{m}$ (a so-called C-band). Again, the tuning range is only $0.012 \mu \mathrm{m}$. Since the Fermi level changes from 0.56 to $0.63 \mathrm{eV}$, one also deals with an unpredicted wavelength variation. Moreover, the waveguide structure is not suitable for the ambient-sensing applications. A graphene-based plasmonic band-pass waveguide filter operating in the far-infrared region has also been presented in Ref. [12]. Unfortunately, the effect of varying ambient refractive index on the resonance wavelength has not been studied in this work.

A graphene-based waveguide band-stop filter reported in Ref. [18] reveals tuning, although its resonance wavelengths are too close to each other. One more plasmonic band-stop filter is composed of periodically modulated graphene deposited over silicon-oxide insulator and multigrating silicon substrate [19]. A wide enough tuning range reached in this study $(37-53 \mathrm{THz})$ is owing to tuning of the chemical voltage applied to graphene waveguide. However, the influence of ambient refractive-index variation on the resonance wavelength has not been mentioned by the authors. Although the graphene-based refractive-index sensor discussed in Ref. [14] is characterized by a high figure of merit ( $7023 \mathrm{~nm} / \mathrm{RIU})$, its resonance-wavelength region is limited to 1-2 $\mu \mathrm{m}$, while the performance at higher wavelengths has not been considered. Finally, the recent study of a tunable dual-band graphene-based infrared reflectance filter discussed in Ref. [20] has reported a high reflectance (0.2) simultaneously at the two resonance wavelengths ( 8 and $13 \mu \mathrm{m})$. Unfortunately, gold used in this study is costly and should be replaced with some inexpensive material, while the effect of ambient refractive index has not been discussed by the authors [20].

In the present study we design and numerically analyze, using a finite-element method, a new plasmonic metamaterial structure that achieves a perfect light absorption at some resonance wavelength. We utilize graphene to tune the resonance wavelength in a wide region of far infrared, via changing the bias voltage. Utilization of rubidium bromide results in a strong energy confinement within the structure. The energy is confined in the dielectric only when the operating wavelength is changed not larger than $0.79 \%$, which is a ratio superior to the figures typical for the other metamaterial-based absorbers known up to date. Moreover, the graphene sheet exposed to the air in our structure changes its conductivity, whereas variations of the refractive index of the air cause a shift in the resonance wavelength.

According to the familiar Kirchhoff's law, a good light absorber would act as a good light emitter whenever it has been heated. For instance, a grating with the metallic surface that absorbs nearly $100 \%$ of the incident light intensity, is expected to act as a black body and so a perfect emitter [21]. Hence, the structure proposed in this work can be applied in many fields such as biosensing, thermal emitting and band-stop filtering. 


\section{Modelling of graphene}

A graphene sheet is composed of a 2D array of structures. Every cell of that array consists of carbon atoms coordinated in hexagonal lattice, thus forming single-atomic cells. The single-layer graphe-ne sheet is thus a semiconductor with a zero gap. These sheets exhibit a linear massless dispersion of electron-hole pairs, while the corresponding Fermi velocity can be as high as $10^{8} \mathrm{~cm} / \mathrm{s}$ [6].

Extraordinary characteristics of the single-layer graphene sheets at the far-infrared frequencies modify the surface current passing through it. Since the graphene surface current varies at different voltage biasing, the conductivity of the graphene surface also can be varied. The graphene surface conductivity at the operating wavelength comes from two different contributions, the intra-band conductivity associated with electron-photon scattering and the inter-band conductivity resulting from direct electron transfer. The intra-band conductivity contribution can be described as follows [6]:

$$
\sigma_{\text {intraband }}=\frac{j e^{2} k_{B} T}{\pi \hbar\left(\omega+j \tau^{-1}\right)}\left[\frac{E_{f}}{k_{B} T}+2 \ln \left(\exp \left(\frac{-E_{f}}{k_{B} T}\right)+1\right)\right]
$$

where $T$ is the absolute temperature, $k_{B}$ the Boltzmann's constant, $e$ the electron charge, $\omega$ the frequency (in $\mathrm{rad} / \mathrm{sec}$ ), $\tau$ the carrier-relaxation lifetime of the electron-phonon scattering in the graphene sheet, $\hbar$ the Planck's constant, and $E_{f}$ the chemical potential that provides the tuning feature.

On the other hand, the inter-band conductivity is given by [6]

$$
\sigma_{\text {intraband }}=\frac{j e^{2}}{4 \pi \hbar} \ln \left[\frac{2\left|E_{f}\right|-\hbar\left(\omega+j \tau^{-1}\right)}{2\left|E_{f}\right|+\hbar\left(\omega+j \tau^{-1}\right)}\right]
$$

Although only the intra-band conductivity is most actual at the far-infrared wavelengths [6], we consider both the intra-band and inter-band contributions in our analysis. The finite-element method integrates a MATLAB code that calculates the total conductivity under specific chemical potential applied.

It is known that chemical-vapour deposition has become a standard and widespread procedure for depositing graphene. This fabrication process yields in extreme thicknesses of the graphene sheets and its peculiar optical and electronic characteristics, which plays an important role when designing high-speed photonic and electronic circuits [6]. The electron-phonon scattering rate of the graphene sheet is equal to $E_{f} \mu /\left(e v_{f}^{2}\right)$, where $\mu$ is the carrier mobility and $v_{f}$ the Fermi velocity that amounts to $10^{6} \mathrm{~m} / \mathrm{s}$ [22]. The carrier mobility approximately equals to $10^{-4} \mathrm{~cm}^{2} /(\mathrm{V} \times \mathrm{s})$, being dependent on the methods used when manufacturing graphene. High-quality processes employed to manufacture graphene, e.g. mechanical exfoliation, can indeed achieve the mobility value mentioned above. Hence, we put the electron-phonon scattering rate to be $0.5 \mathrm{ps}$ in the following analysis. Our numerical analysis is performed for the room temperature, $300 \mathrm{~K}$ (see Ref. [23]).

\section{Geometry of metamaterial and construction of our device}

The unit cell of our plasmonic metamaterial structure is composed of a metal (aluminium), a dielectric (rubidium bromide) and a graphene sheet deposited above the dielectric and below the periodic array of rhombic-shaped aluminium parts. The aluminium substrate in this structure is $100 \mathrm{~nm}$ thick, whereas the $\mathrm{RbBr}$ dielectric has a thickness of $300 \mathrm{~nm}$. Finally, the rhombic-shaped array of aluminium parts with the thicknesses of $100 \mathrm{~nm}$ lies above graphene. Fig. 1 shows the geometry of our structure.

Ukr. J. Phys. Opt. 2019, Volume 20, Issue 1 


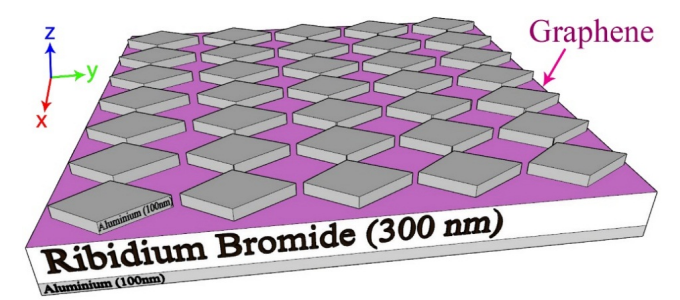

Fig. 1. 3D view of our metamaterial structure.

As seen from Fig. 2, every rhombic aluminium cell has the height $9900 \mathrm{~nm}$ along $Y$ axis and the width $4900 \mathrm{~nm}$ along $X$ axis. Here the spacing between the neighbouring edges of the rhombic aluminium parts is $100 \mathrm{~nm}$. A COMOSL materials library can readily provide all the optical parameters needed, e.g., the refractive indices of subwavelength-structured materials.

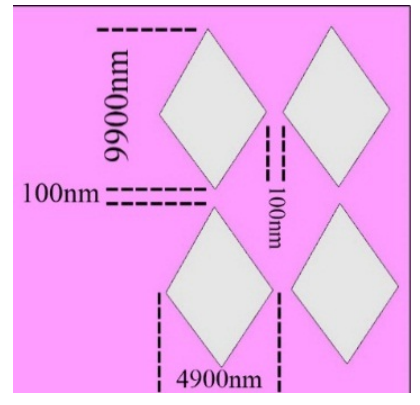

Fig. 2. Top-view of our metamaterial structure.

\section{Numerical analysis and simulation results}

The finite-element method makes use of periodic conditions at the edges of single cells of the rhombic-shaped aluminium part. To demonstrate the size of light absorption in our metamaterial structure, we apply a normally incident electric field polarized in the $Y$ direction. Rubidium bromide confines the light energy within it and prevents light reflection at the resonance wavelength at particular graphene chemical potentials. Fig. 3 and Fig. 4 illustrate spatial distributions of the squared magnetic field component $\left|H_{x}\right|^{2}$ at $26.6 \mu \mathrm{m}$ and the chemical potential $0.3 \mathrm{eV}$. This corresponds to a confinement at the middle thicknesses of rubidium bromide.

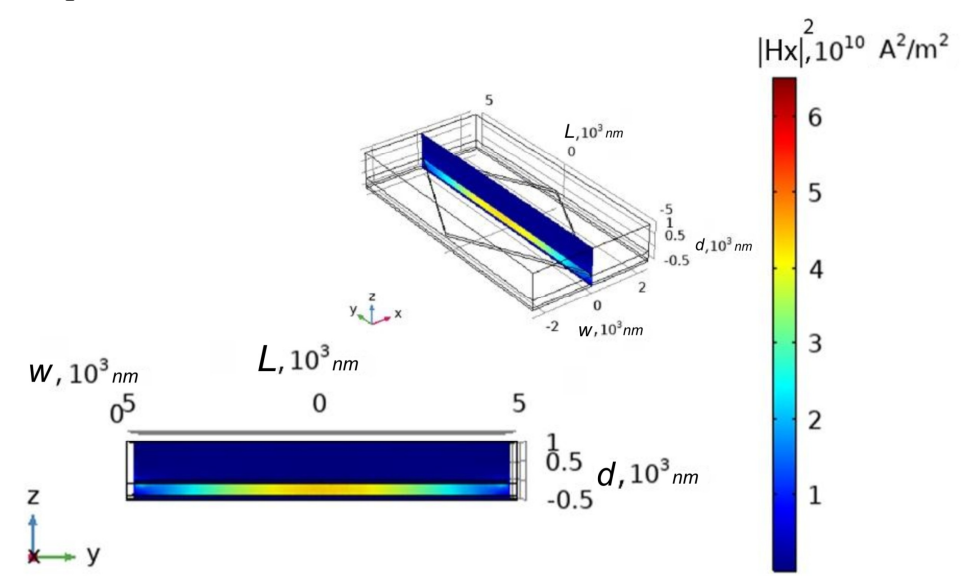

Fig. 3. Side view of $\left|H_{x}\right|^{2}$ distribution at $26.6 \mu \mathrm{m}$, as calculated at the graphene's chemical potential $0.3 \mathrm{eV}$ and the resonance wavelength $26.6 \mu \mathrm{m}$ (the frequency $11.27 \mathrm{THz}$ ): $L, w$ and $d$ imply respectively length, width and height of our structure. 


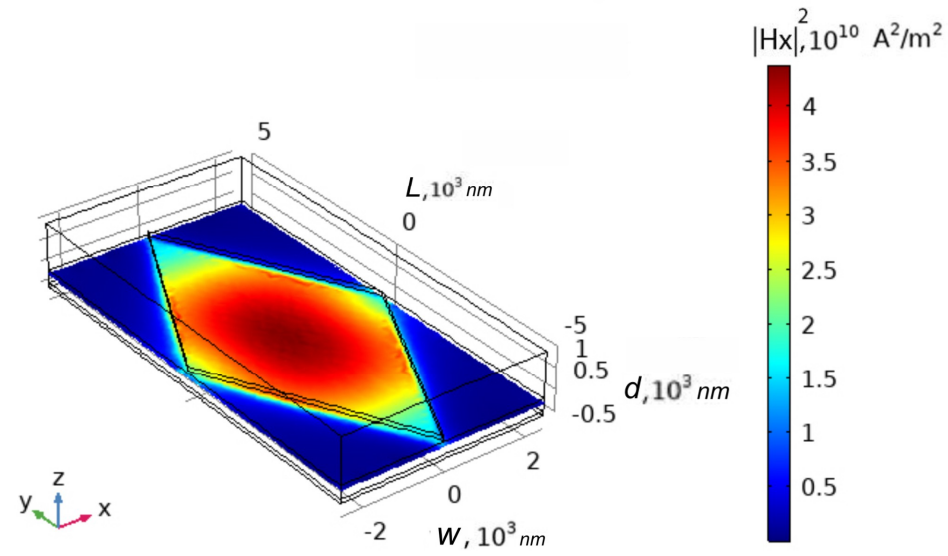

Fig. 4. Cross-section view of $\left|H_{x}\right|^{2}$ distribution at $26.6 \mu \mathrm{m}$, as calculated at the graphene's chemical potential $0.3 \mathrm{eV}$ and the resonance wavelength $26.6 \mu \mathrm{m}$ (the frequency $11.27 \mathrm{THz}$ ): $L, w$ and $d$ imply respectively length, width and height of our structure.

As seen from Fig. 3 and Fig. 4, a strong light-energy confinement is available within the size, which is small if compared with the resonance wavelength. This testifies that a localized surface plasmon-polariton has been successfully excited in our structure. Fig. 5 shows the reflection spectra simulated for the graphene-based periodic rhombic-shaped structure under the conditions of normal-incidence excitation with the electric field along the $Y$ axis. From the above results, one can see a notable red-shifting behaviour of the resonance wavelength imposed by increasing chemical potential of graphene.

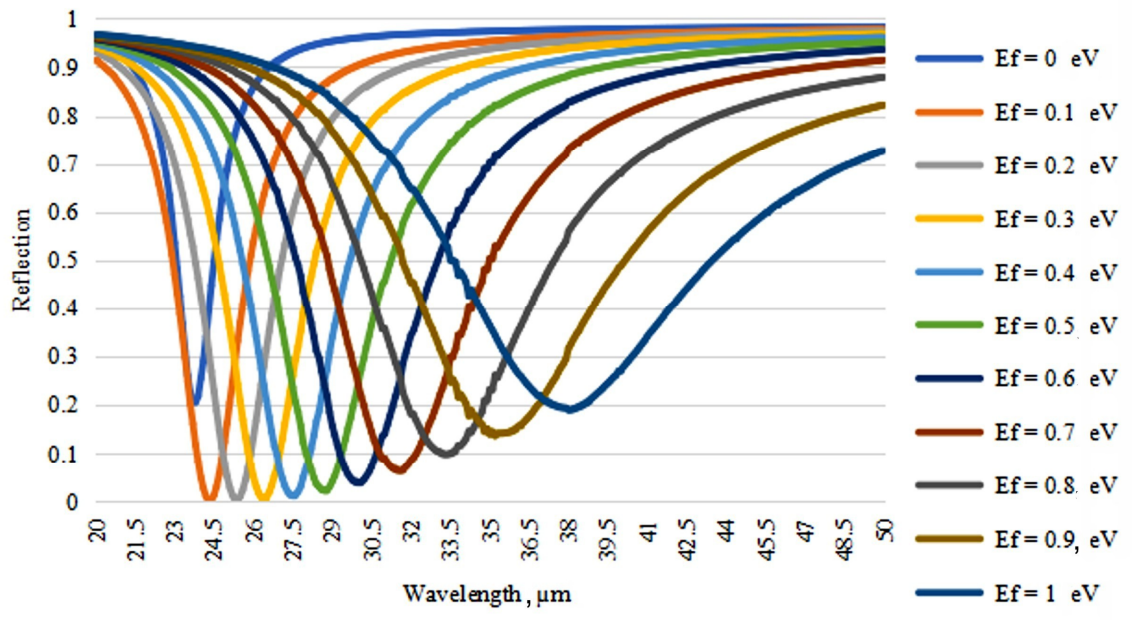

Fig. 5. Dependences of reflection of our metamaterial structure on the light wavelength, as calculated at different chemical potentials of graphene shown in the legend.

The red shift can be readily understood in terms of behaviour of the graphene conductivity (see Eqs. (1) and (2)). The changes in the chemical potential of the graphene sheet, which are stipulated by a DC source, result in varying surface conductivity. Here the DC source is applied electrostatically, by connecting a conductive contact between the single-layer graphene sheet and the aluminium reflector (acting as an electrostatic ground). The changes in the graphene conductivity lead to changing surface current density $\overrightarrow{\boldsymbol{j}}$, due to the evident relation $\overrightarrow{\boldsymbol{j}}=\sigma \overrightarrow{\boldsymbol{E}}$. According to the Maxwell's equation, we have 


$$
\nabla \times \overrightarrow{\boldsymbol{H}}=\overrightarrow{\boldsymbol{J}}+\varepsilon \frac{\partial \overrightarrow{\boldsymbol{E}}}{\partial t}
$$

where $\overrightarrow{\boldsymbol{j}} \neq 0$. Then the resonance wavelength can be changed by any changes in the chemical potential (i.e., changes in the conductivity $\sigma$ ). These changes appear because the conductivity is a function of the carrier relaxation lifetime $\tau$, which is in its turn a function of the electron mobility (see Eqs. (1) and (2)). This is why the changes occurring in the chemical potential result in changing electron mobility at fixed electron-phonon scattering rate and fixed carrier velocity. Then the changes in the conductivity also follow (see Ref. [22]).

Fig. 5 shows that our plasmonic metamaterial-based structure exhibits a zero reflection at some chemical potentials (e.g., at $E_{f}=0.1,0.2,0.3$ and $0.4 \mathrm{eV}$ ), i.e. the structure acts as a perfect absorber and a band-stop filter. The feature of perfect absorption is due to a highly localized surface plasmon-polariton, which confines most of the magnetic-field energy inside the $\mathrm{RbBr}$ insulator in a certain wavelength region. When $E_{f}$ increases, the reflection spectrum broadens because of degradation in the quality factor due to the metal losses in this wavelengths region. It is worth noting that, when $E_{f}$ changes from 0 to $1 \mathrm{eV}$, we observe large changes of the resonance wavelength. As evidenced by Fig. 5, there is a red shift of about $14.4 \mu \mathrm{m}$, so that the working wavelength can be changed from 23.8 to $38.2 \mu \mathrm{m}$. This feature provides a wide tunability of our structure, which is very useful for various applications.

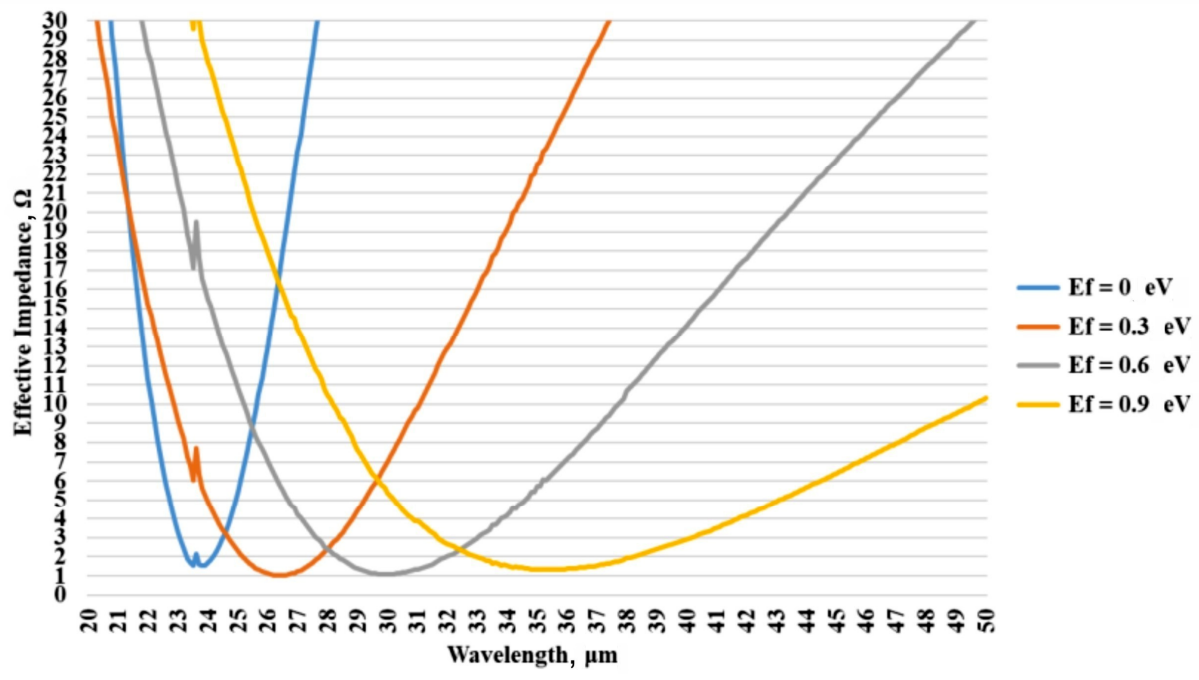

Fig. 6. Effective impedances of our plasmonic metamaterial as functions of light wavelength. Calculations are performed at different chemical potentials of graphene shown in the legend.

Another possible interpretation of our plasmonic metamaterial absorber is that the effective impedance of the metamaterial structure can reach a unit value, similar to that of the air. Hence, the light passes through the material with no reflection. The impedance $Z$ is related to the standard $S$ parameters via $[24,25]$ :

$$
Z=\mp \sqrt{\frac{\left(1+S_{11}\right)^{2}-S_{21}^{2}}{\left(1-S_{11}\right)^{2}-S_{21}^{2}}},
$$

where $S_{11}$ is the reflection from our absorber and $S_{21}$ the transmission through it. Utilization of the aluminium substrate prevents any transmission through the structure, so that $S_{21}$ equals to zero at any operating wavelength. Then Eq. (4) reduces to 


$$
Z=\mp \frac{\left(1+S_{11}\right)}{\left(1-S_{11}\right)},
$$

Fig. 6 shows the effective impedance of our metamaterial structure versus the light wavelength, as calculated at different Fermi levels $E_{f}$ of graphene.

\section{Metamaterial structure as a sensor}

As a matter of fact, the graphene sheet in our plasmonic metamaterial structure can act as a sensor. Indeed, the resonance wavelength changes whenever the ambient of our structure does. Then another important application of our structure becomes possible, a refractive-index sensor. For each chemical potential of the graphene sheet, we achieve a different wavelength sensing range. Fig. 7 shows dependences of the resonance wavelength upon the ambient refractive index. They have been calculated at different chemical potentials of the graphene sheet. For instance, if we set the chemical potential to be $0.9 \mathrm{eV}$, the resonance wavelength changes from 35.4 to $38.8 \mu \mathrm{m}$ under the condition that the refractive index of the ambient varies from 1.0 to 1.5. This gives the sensitivity $6.8 \mu \mathrm{m} / \mathrm{RIU}$. As seen from Fig. 7, the sensitivity depends also on the value of Fermi level.

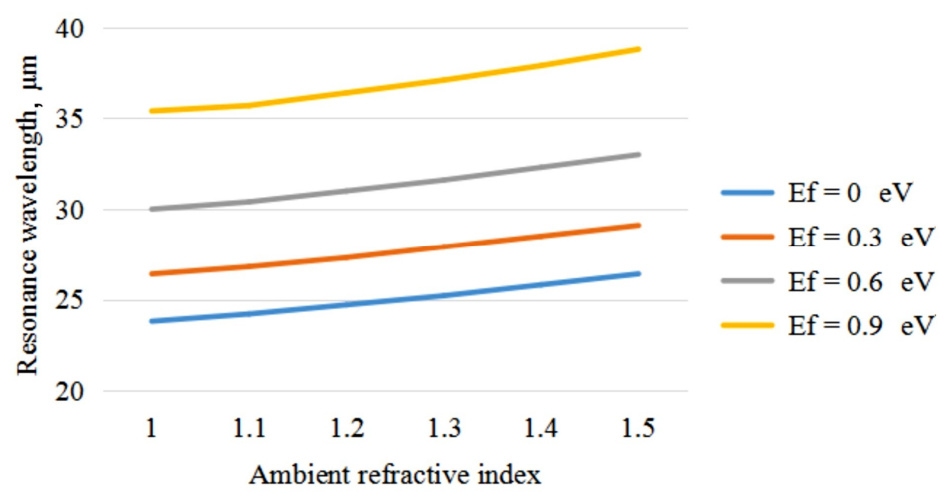

Fig. 7. Resonance wavelength versus ambient refractive index, as calculated at different $E_{f}$ values.

\section{Conclusion}

In the present work we have suggested a highly efficient and tunable absorber designed using a plasmonic metamaterial, which can work in the far-infrared region. When compared to the other plasmonic absorbers based upon metamaterials, our structure demonstrates a high energy confinement within small sizes compared with the resonance wavelength (i.e., a property of subwavelength confinement). Moreover, our device avoids the use of gold or silver, being based on cheap materials. We believe that the absorber designed using the plasmonic metamaterial is simpler and more practical than the tunable absorbers reported in the earlier literature. Its noticeable features are wide-range tunability and high absorption efficiency for the far-infrared wavelengths. Finally, one can tune the sensitivity of the device by changing the chemical potential of graphene.

\section{References}

1. Vatansever F and Hamblin M R, 2012. Far infrared radiation (FIR): its biological effects and medical applications. Photon. Lasers Med. 4: 255-266.

2. Wei Z, Li X, Yin J, Huang R, Liu Y, Wang W, Liu H, Meng H and Liang R, 2016. Active plasmonic band-stop filters based on graphene metamaterial at THz wavelengths. Opt. Express. 24: $14344-14351$.

Ukr. J. Phys. Opt. 2019, Volume 20, Issue 1 
3. Stefan A M. Plasmonics: fundamentals and applications. Springer: Science+Business Media LLC (2007).

4. Alipour A H and Mir A, 2018. Design and simulation of a high-selective plasmon-induced reflectance in coupled dielectric-metal-dielectric nano-structure for senor devices and slow light propagation. Plasmonics. 1-11.

5. Li H, Qin M, Wang L, Zhai X, Ren R and Hu J, 2017. Total absorption of light in monolayer transition-metal dichalcogenides by critical coupling. Opt. Express. 25: 31612-31621.

6. Chen P Y and Alù A, 2011. Atomically thin surface cloak using graphene monolayers. ACS Nano. 5: 5855-5863.

7. Serebryannikov A E, Hajian H, Beruete M, Ozbay E and Vandenbosch G A E, 2018. Tunable deflection and asymmetric transmission of $\mathrm{THz}$ waves using a thin slab of graphene-dielectric metamaterial, with and without ENZ components. Opt. Mater. Express. 8: 3887-3898.

8. Ogawa S, Shimatani M, Fukushima S, Okuda S and Matsumoto K, 2018. Graphene on metalinsulator-metal-based plasmonic metamaterials at infrared wavelengths. Opt. Express. 26: 5665-5674.

9. Bludov Y V, Vasilevskiy M I and Peres N M R, 2012. Tunable graphene-based polarizer. J. Appl. Phys. 112: 84320.

10. Huang J, Yang J, Zhang H, Zhang J, Wu W and Chang S, 2016. Analysis of tunable flat-top bandpass filters based on graphene. IEEE Photon. Technol. Lett. 28: 2677-2680.

11. Ren J and Yin J Y, 2018. Cylindrical-water-resonator-based ultra-broadband microwave absorber. Opt. Mater. Express. 8: 2060-2071.

12. Danaeifar M, Granpayeh N, Mohammadi A and Setayesh A, 2013. Graphene-based tunable terahertz and infrared band-pass filter. Appl. Opt. 52: E68-E72.

13. Lumeau J and Glebov L B, 2013. Modeling of the induced refractive index kinetics in photothermo-refractive glass. Opt. Mater. Express. 3: 95-104.

14. Yang Q, Qin L, Cao G, Zhang C and Li X, 2018. Refractive index sensor based on graphenecoated photonic surface-wave resonance. Opt. Lett. 43: 639-642.

15. Liu M, Yin X, Ulin-Avila E, Geng, T. Zentgraf B, Ju L, Wang F and Zhang X, 2011. A graphene-based broadband optical modulator. Nature. 474: 64.

16. Fuentecilla-Carcamo I, Palomino-Ovando M and Ramos-Mendieta F, 2017. One dimensional graphene based photonic crystals: Graphene stacks with sequentially-modulated doping for photonic band gap tailoring. Superlattices Microstruct. 112: 46-56.

17. Vakil A and Engheta N, 2011. Transformation optics using graphene. Science. 332: 12911294.

18. Cai Y, Xu K D, Guo R, Zhu J and Liu Q H, 2018. Graphene-based plasmonic tunable dualband bandstop filter in the far-infrared region. IEEE Photon. J. 10: 1-9.

19. Shi B, Cai W, Zhang X, Xiang Y, Zhan Y, Geng J, Ren M and Xu J, 2016. Tunable band-stop filters for graphene plasmons based on periodically modulated graphene. Sci. Rep. 6: 2679626802.

20. Goldflam M D, Ruiz I, Howell S W, Wendt J R, Sinclair M B, Peters D W and Beechem T E, 2018. Tunable dual-band graphene-based infrared reflectance filter. Opt. Express. 26: 85328541.

21. Wang C M, Chang Y C, Abbas M N, Shih M H and Tsai D P, 2009. T-shaped plasmonic array as a narrow-band thermal emitter or biosensor. Opt. Express. 17: 13526-13531. 
22. Yao G, Ling F, Yue J, Luo C, Ji J and Yao J, 2016. Dual-band tunable perfect metamaterial absorber in the THz range. Opt. Express. 24: 1518-1527.

23. Mou N, Sun S, Dong H, Dong S, He Q, Zhou L and Zhang L, 2018. Hybridization-induced broadband terahertz wave absorption with graphene metasurfaces. Opt. Express. 26: 1172811736.

24. Chen X, Grzegorczyk T M, Wu B I, Pacheco J and Kong J A, 2004. Robust method to retrieve the constitutive effective parameters of metamaterials. Phys. Rev. E. 70: 16608.

25. Smith D R, Schultz S, Marko P and Soukoulis C M, 2002. Determination of effective permittivity and permeability of metamaterials from reflection and transmission coefficients. Phys. Rev. B. 65: 195104.

Mohammed Nadhim Abbas and Farooq Abdulghafoor Khaleel. 2019. Wide-range tunable subwavelength band-stop filter for the far-infrared wavelengths based on single-layer graphene sheet. Ukr.J.Phys.Opt. 20: 37 - 45. doi: 10.3116/16091833/20/1/37/2019

Анотація. Запропоновано перестроюваний субхвильовий метаматеріал, який складається з масиву алюмінієвих провідників, $і$ чисельно проаналізовано його з використанням методу скінченних елементів. Запропоновано використовувати ией матеріал для побудови активного фільтра затримки в далекій інфрачервоній області. Кожна комірка структури на метаматеріалі складається з алюмінієвого провідника ромбічної форми, діелектрика (броміду рубідію) і графенового листа, нанесеного на діелектрик для досягнення ефекту перестроювання. Сильний конфайнмент електромагнітної енергї, поглинутої $в$ діелектрику, приводить до високоефективної функиії поглинача. Запропонована структура з графеновим листом, піддана впливові повітря, можу слугувати високочутливим давачем показника заломлення (чутливість 6,8 мкм/RIU). Завдяки невеликим розмірам структури, вона виявляє ідеальне поглинання в області далеких інфрачервоних хвиль і широкий діапазон поглинання (від 23,6 до 38,1 мкм). Метаматеріали з описаною структурою сприятимуть побудові ідеальних поглиначів для біомедичних сенсорів. 